Article

\title{
How Does the Preparation of Rye Porridge Affect Molecular Weight Distribution of Extractable Dietary Fibers?
}

\author{
Allah Rakha *, Per Åman and Roger Andersson \\ Department of Food Science, Swedish University of Agricultural Sciences, Box, 7051, S-75007 \\ Uppsala, Sweden; E-Mails: Per.Aman@slu.se (P.A.); Roger.Andersson@slu.se (R.A.) \\ * Author to whom correspondence should be addressed; E-Mail: Allah.Rakha@slu.se; \\ Tel.: +46-18-672-063; Fax: +46-18-672-995.
}

Received: 27 February 2011; in revised form: 6 April 2011 / Accepted: 13 May 2011 /

Published: 24 May 2011

\begin{abstract}
Extractable dietary fiber (DF) plays an important role in nutrition. This study on porridge making with whole grain rye investigated the effect of rest time of flour slurries at room temperature before cooking and amount of flour and salt in the recipe on the content of DF components and molecular weight distribution of extractable fructan, mixed linkage $(1 \rightarrow 3)(1 \rightarrow 4)-\beta$-D-glucan ( $\beta$-glucan) and arabinoxylan $(\mathrm{AX})$ in the porridge. The content of total DF was increased (from about $20 \%$ to $23 \%$ of dry matter) during porridge making due to formation of insoluble resistant starch. A small but significant increase in the extractability of $\beta$-glucan $(P=0.016)$ and $\mathrm{AX}(P=0.002)$ due to rest time was also noted. The molecular weight of extractable fructan and AX remained stable during porridge making. However, incubation of the rye flour slurries at increased temperature resulted in a significant decrease in extractable AX molecular weight. The molecular weight of extractable $\beta$-glucan decreased greatly during a rest time before cooking, most likely by the action of endogenous enzymes. The amount of salt and flour used in the recipe had small but significant effects on the molecular weight of $\beta$-glucan. These results show that whole grain rye porridge made without a rest time before cooking contains extractable DF components maintaining high molecular weights. High molecular weight is most likely of nutritional importance.
\end{abstract}

Keywords: whole grain rye; porridge making; arabinoxylan; fructan; $\beta$-glucan; molecular weight 


\section{Introduction}

Rye (Secale cereale L.) is an important cereal crop in Eastern and Northern Europe and a rich source of soluble and insoluble dietary fiber (DF) [1]. The typical rye grain contains 18 to $22 \%$ DF [2] or 14 to $21 \%$ when fructan is not included in the analysis [3]. The major components of rye DF are arabinoxylan $(\mathrm{AX})$, fructan, and mixed linkage $(1 \rightarrow 3)(1 \rightarrow 4)-\beta$-D-glucan $(\beta$-glucan), with contents ranging from $8.0-12.1 \%, 4.5-6.4 \%$, and $1.3-2.2 \%$, respectively. The water soluble/extractable part of $\mathrm{DF}$ mainly comprises fructan and some $\mathrm{AX}$ and $\beta$-glucan, while the majority of the insoluble part consists of $\beta$-glucan and $\mathrm{AX}$, as well as cellulose, Klason lignin, and small amounts of other polymers [2].

Cereal AX is a diverse group of polysaccharides based on a linear chain of 4-linked- $\beta$-D-xylopyranosyl residues substituted at O-2 and/or O-3 positions with $\alpha$-L-arabinofuranosyl residues [4]. The polymer may also contain other sugar residues and phenolic substituents. Cereal $\beta$-glucan consists of about $70 \%$ 4-linked and 30\% 3-linked $\beta$-D-glucopyranosyl residues, with some differences between species [5]. Fructan is a highly soluble DF component with prebiotic properties [6]. Chemically, fructan consists of $\beta$-linked oligomers and polymers of D-fructose with a terminal sucrose residue [7].

The European Food Safety Authority dietary guidelines (EFSA-Q-2008-467) recommend at least $25 \mathrm{~g} \mathrm{day}^{-1}$ intake of DF for adults, while the typical Western diet gives less than $20 \mathrm{~g} \mathrm{DF}$ day $^{-1}$ [8]. Food authorities in many countries therefore recommend an increased intake of DF, and rye is the cereal with the highest DF content as shown in the database of United States Department of Agriculture [9]. The major benefits associated with DF are stool bulking effects, increased satiety, and reduced risk of developing type 2 diabetes and coronary heart disease [10,11]. Both the quantity and quality of the DF components are probably of importance in governing these physiological functions and health effects [12].

In the Nordic countries, rye is often consumed in the form of traditional whole grain soft breads and crispbreads, porridge and breakfast cereals. Porridge making is an easy and traditional way to prepare cereals for consumption, as it does not involve rigorous processing and the product retains its $\beta$-glucan molecular weight and viscosity better than bread or pasta [13,14]. It is known that the appearance of porridge differs depending on whether the cereal is added to cold or hot water before cooking. This difference may be at least partly related to changes in properties of the soluble DF components. Processing parameters, such as heating, mixing, and fermentation, have been reported to influence the content, structure, solubility, and properties of cereal DF [15-18]. Furthermore, endogenous and contaminating microbial enzymes present in the flour become active after hydration and can modify the DF components $[15,17]$. The activity of endogenous enzymes in rye grains is known to reduce extract viscosity [19] and influence the baking process and the quality of the bread [20].

Hence, knowledge of processing and enzyme-related modifications of cereal DF is of great importance. The main aim of this study was to examine potential changes in the molecular weight distribution of major extractable DF components (arabinoxylan, fructan, and $\beta$-glucan) during preparation of rye porridge. 


\section{Results and Discussion}

\subsection{Content of Dietary Fiber and Its Components}

The DF content of the whole grain rye flour used was about $20 \%$, which is similar to previously reported values [2]. As a result of porridge making, the DF content increased to more than $23 \%$ (Table 1), most likely due to formation of resistant starch [21]. The total contents of DF, AX, $\beta$-glucan, and fructan in the two porridges were similar and not significantly affected by rest time before cooking. However, a small but statistically significant $(P=0.002)$ increase in the content of extractable AX was noted over the $60 \mathrm{~min}$ rest time. The extractable $\beta$-glucan content was $0.39 \%$ at $0 \mathrm{~min}$ rest time and increased by $41 \%$ to $0.55 \%(P=0.016)$ after $60 \mathrm{~min}$ of rest time (Figure 1$)$. These results clearly show that these dietary fiber components had a higher solubility after resting and that they were not hydrolyzed to small fragments or degraded to components not included in the content analyses. Increased solubilization of $\mathrm{AX}$ and $\beta$-glucan due to endogenous enzymes has also been reported during bread making [15,17,22,23]. Amount of salt or flour did not affect $\beta$-glucan extractability significantly.

Table 1. Content (\% dry matter) of dietary fiber (DF) and major DF components in rye flour and two porridges prepared with $42.5 \mathrm{~g}$ flour and $0.5 \mathrm{~g}$ salt and rested for 0 or $60 \mathrm{~min}$ before cooking. Means of double analysis of three experimental replicates, expressed on a dry matter basis ${ }^{1}$.

\begin{tabular}{|c|c|c|c|c|c|c|c|}
\hline \multirow{2}{*}{ Sample } & \multicolumn{2}{|l|}{$\mathrm{DF}^{2}$} & \multicolumn{2}{|c|}{ Arabinoxylan $^{3}$} & \multicolumn{2}{|c|}{$\beta$-Glucan } & \multirow{2}{*}{$\begin{array}{l}\text { Fructan } \\
\text { Extractable } \\
\end{array}$} \\
\hline & Total & Extractable & Total & Extractable & Total & Extractable & \\
\hline Flour & 20.2 & 7.5 & 8.2 & 2.5 & 2.2 & 0.31 & 4.2 \\
\hline Porridge, without rest time & 23.2 & 7.3 & 8.6 & 2.5 & 2.3 & 0.39 & 3.9 \\
\hline Porridge, with 60 min rest time & 23.5 & 7.7 & 8.6 & 2.6 & 2.3 & 0.55 & 4.1 \\
\hline
\end{tabular}

${ }^{1}$ The deviation in analytical results is generally below $5 \% ;{ }^{2}$ Including fructan; ${ }^{3}$ Calculated after subtracting arabinose residues in arabinogalactan, as described in materials and methods.

Figure 1. Main effects plot for extractable $\beta$-glucan (\% of dry matter) and Calcofluor average molecular weight of $\beta$-glucan $\left(M_{c f}\right)$ in porridge.
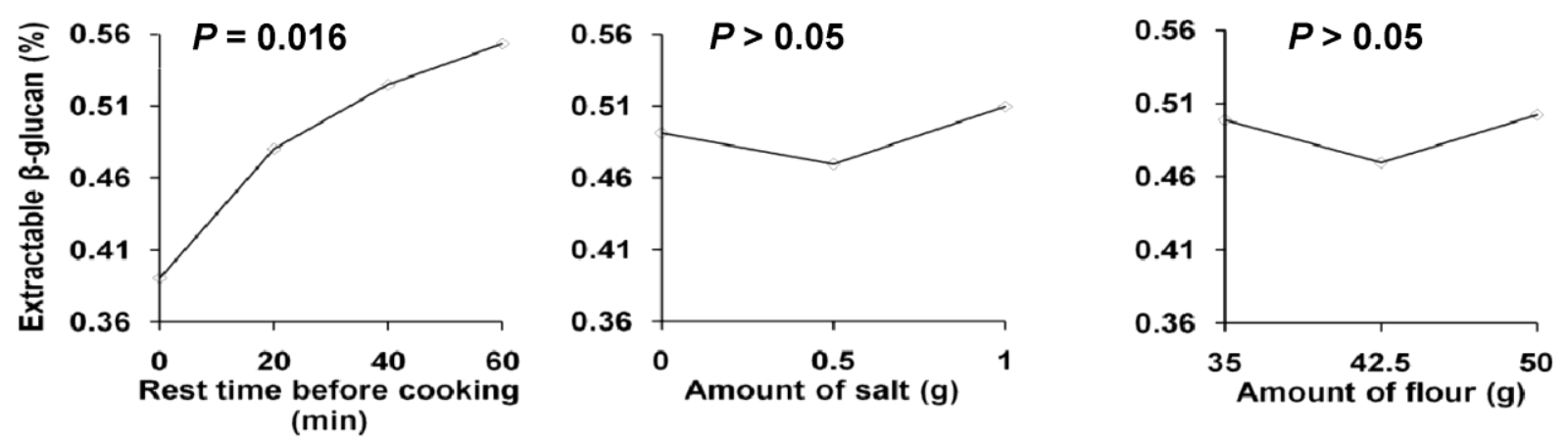
Figure 1. Cont.
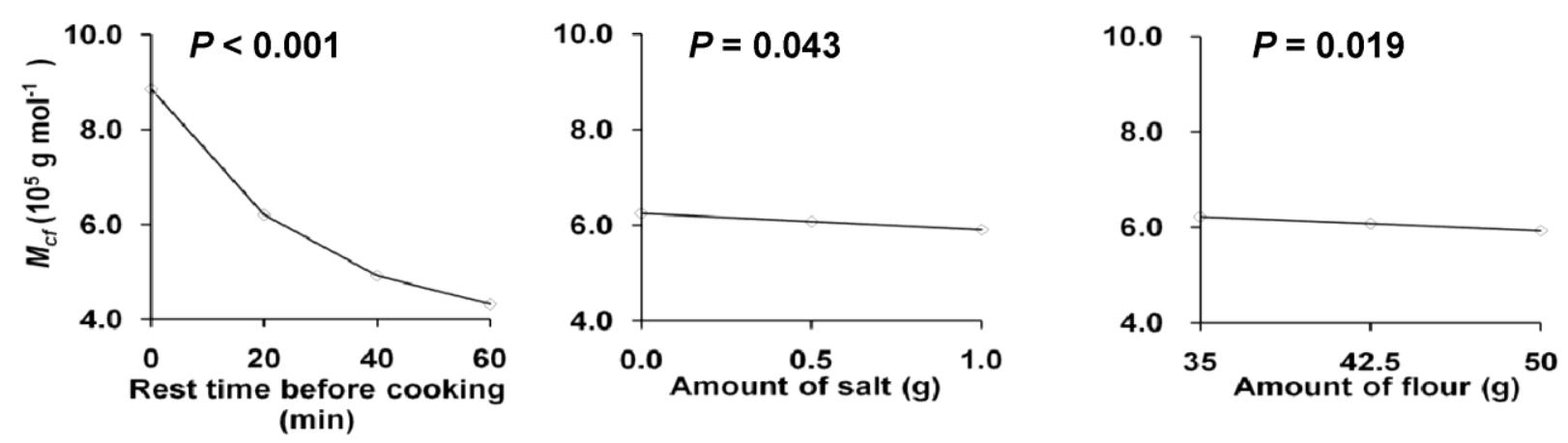

\subsection{Molecular Weight Distribution of DF Components}

Measurement of molecular weight is a more sensitive way to assess process-induced changes in DF components. The molecular weight distribution of three major DF components, i.e., fructan, $\beta$-glucan, and $\mathrm{AX}$, in whole grain rye flour and porridges is described in the following sections.

\subsubsection{Molecular Weight Distribution of Fructan}

Pre-trials were conducted to examine the effect of heating on the molecular weight distribution of fructan, since one of the aims of this study was to get an overview of fructan degradation during porridge making. Interestingly, there were no visible effects of increasing the cooking time (2, 10, $20 \mathrm{~min})$ on the distribution of fructan with different degrees of polymerization (DP) (results not shown). Therefore cooking time was excluded as a factor in the experimental design.

In the main experiment, the effects of salt, amount of flour and rest time of flour slurry before cooking on the relative DP distribution of fructan were non-significant (Figure 2). However, the rye flour had slightly more long-chain fructan compared with all porridges tested. The chromatograms for flour and porridge rested for $60 \mathrm{~min}$ were very similar (Figure 3). This indicates great stability of fructan during rye porridge making, and thus endogenous fructan hydrolases (FEHs), if present, appear to have very low activity. The DP distribution is only based on relative area and is thus likely to overestimate short oligomers, but this fact does not affect the conclusion that the fructan were stable. The complexity of linkages in cereal fructan and the specificity of FEHs might be the reason for the stability of fructan to endogenous enzymes in rye [24,25]. Another reason for the stability of fructan during resting in this study could be the sub-optimal temperature and $\mathrm{pH}\left(20^{\circ} \mathrm{C}\right.$ and 6.2 , respectively), since the optimum temperature and $\mathrm{pH}$ for $\mathrm{FEH}$ activity have been shown to be around $40{ }^{\circ} \mathrm{C}$ and 4.5-5.5, respectively [26,27]. This stability of rye fructan to endogenous enzymes has also been observed during bread making, where breads made without yeast contain nearly as much fructan as the original rye grain $[2,28]$. This is an important consideration for modern processing of rye products, where the aim is to avoid losses of physiological functions associated with DF components. 
Figure 2. Relative distribution of fructan with different degrees of polymerization (DP) in whole grain rye flour and porridges prepared according to the experimental design. Results are computed from differences in peak areas of non-fructanase and fructanase treated extracts.

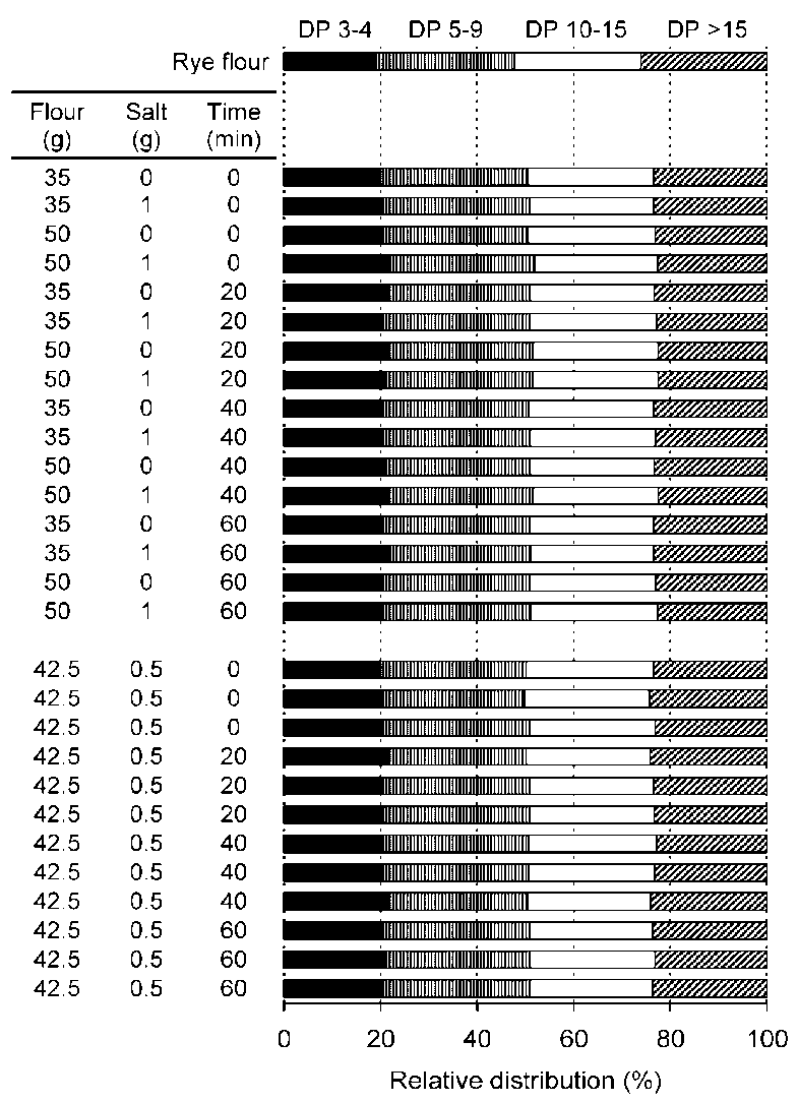

Figure 3. Chromatograms showing distribution of fructan in whole grain rye flour and porridge rested for $60 \mathrm{~min}$ before cooking. Dotted line ( ......) shows chromatogram after fructanase treatment.

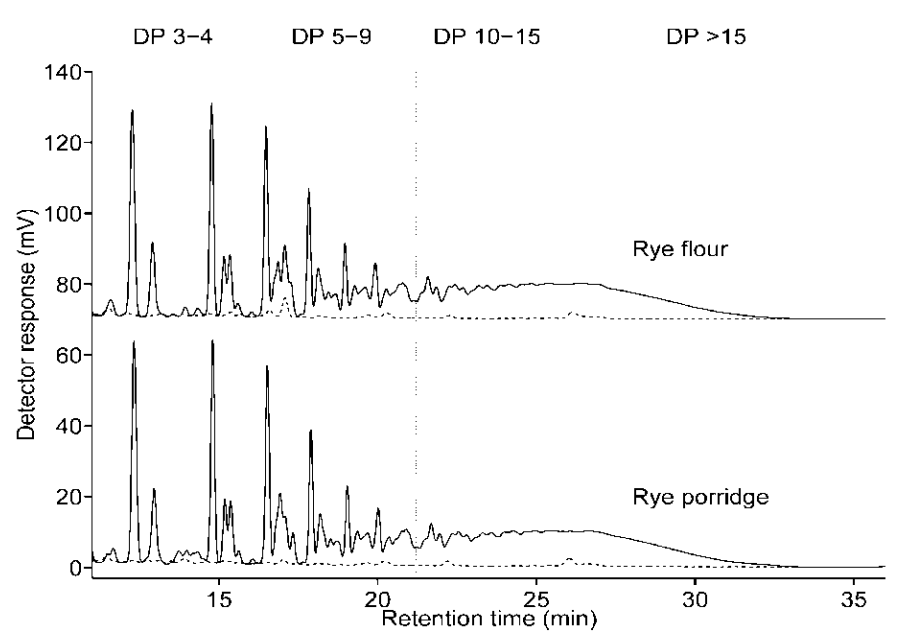

\subsubsection{Molecular Weight Distributions of Arabinoxylan}

Weight average molecular weight $\left(M_{w}\right)$ and number average molecular weight $\left(M_{n}\right)$ of extractable arabinoxylan were not significantly influenced by the amount of salt and flour in the recipe or the rest 
time during porridge making. This indicates the stability of arabinoxylan molecules during resting at $20{ }^{\circ} \mathrm{C}$ for $1 \mathrm{~h}$ and cooking of wholegrain rye porridge, as revealed by the molecular weight distribution profiles (Figure 4). The $M_{w}$ of AX in flour extract $\left(12 \times 10^{5} \mathrm{~g} \mathrm{~mol}^{-1}\right)$ was slightly lower than in extracts of porridges (on average $14 \times 10^{5} \mathrm{~g} \mathrm{~mol}^{-1}$ ) probably due to an increased extractability of high molecular weight fractions in porridge. Sub-optimal temperature $\left(20{ }^{\circ} \mathrm{C}\right)$ and $\mathrm{pH}(6.2)$ during incubation were assumed to be responsible for non-existent activity of endogenous xylanases during the rest time. To test these hypotheses, rye flour slurries were incubated in an oven for $1 \mathrm{~h}$ at variable temperatures $\left(20,35,45,55^{\circ} \mathrm{C}\right)$ and $\mathrm{pH}$ values (4.5 or 6.2) as described in experiment 2 of experimental section. The results from this investigation showed a significant decrease $(P=0.012)$ in $\mathrm{AX} M_{w}$ as a result of increasing temperature, confirming our assumption about sub-optimal temperature during incubation being one possible reason for $\mathrm{AX}$ molecular weight stability (Figure 5). The optimum temperature for major rye AX-degrading enzymes, i.e., endo-( $1 \rightarrow 4)-\beta$-D-xylanase (EC 3.2.1.8), $\alpha$-L-arabinosidase (EC 3.2.1.55), and $\beta$-D-xylosidase (EC 3.2.1.37), has been reported to be $40{ }^{\circ} \mathrm{C}$, $60{ }^{\circ} \mathrm{C}$ and $70{ }^{\circ} \mathrm{C}$, respectively, and the optimum $\mathrm{pH}$ around 4.5 [18]. However, the effect of $\mathrm{pH}$ on $\mathrm{AX}$ $M_{w}$ was non-significant ( $P>0.05$, Figure 5).

Figure 4. Molecular weight distribution of arabinoxylan in flour ( - ) and in porridges rested for $0 \min (----)$ and $60 \min (\cdots+$.$) ) before cooking.$

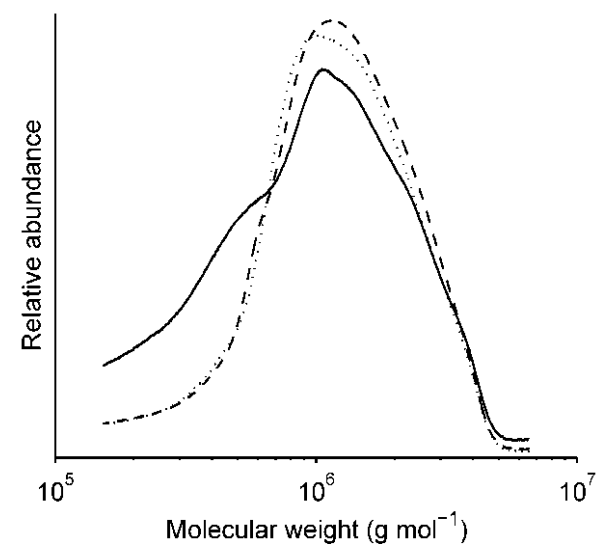

Figure 5. Effect of incubation temperature in rye flour slurries prepared with water (pH 6.2) and buffer ( $\mathrm{pH} 4.5)$ on weight average molecular weight $\left(M_{w}\right)$ of rye arabinoxylan $(\diamond \mathrm{pH} 6.2 ; \square \mathrm{pH} 4.5)$. The bars describe the standard error of mean (SEM).

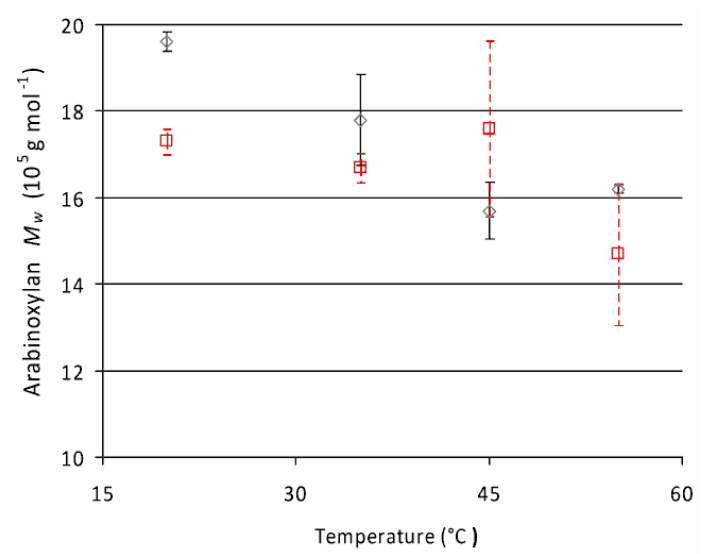


In contrast to porridge making, bread making normally involves dough proofing at $40-45{ }^{\circ} \mathrm{C}$, which is the optimal temperature for yeast to work [29]. The dough proofing temperature is also ideal for endo-( $1 \rightarrow 4)-\beta$-D-xylanase, which hydrolyses the $\beta(1 \rightarrow 4)$-D-xylosidic linkage $[18,19]$. Furthermore, sourdough is used extensively in rye bread making to give the bread a characteristic flavor. The $\mathrm{pH}$ of sourdough (3.5-4.5) is usually closer to the optimum for endogenous xylanases [30], and relatively more AX degradation has been reported in sourdough bread compared with yeast or air-leavened crispbread [2].

Alongside endo- $(1 \rightarrow 4)-\beta$-D-xylanase, $\alpha$-L-arabinosidase liberates arabinose side-chains from the xylan backbone, while $\beta$-D-xylosidase attacks the non-reducing end of xylo-oligosaccharides and produces xylose monomers [19,31]. Other de-branching enzymes such as feruloyl esterase (EC 3.1.1.73), $\alpha$-glucuronidase (3.2.1.139), and acetyl- and acetyl-xylan esterases (3.1.1.6 \& 3.1.1.72) might be required for complete hydrolysis of $\mathrm{AX}$, depending upon the complexity of branching on the xylan backbone [32]. The presence of multiple cross-linkages of AX with other polymers and side-chains ensures maximum stability. The extent of branching usually controls the solubility and enzyme action on AX molecules [4].

Xylanase activity may also arise from the microbial community present on the surface of cereal grains [17,33], and thus the activity is also determined by pre-processing of the grains before milling. The presence of Triticum aestivum xylanase inhibitor (TAXI) and xylanase inhibitor protein (XIP) along with some chemical inhibitors also contributes to the stability of AX in rye products [34,35]. The activity of endogenous enzymes and inhibitors depends on multiple factors, e.g., cultivar, growth conditions, pre-harvest sprouting, storage conditions, milling fractionation, and processing conditions [19,35].

\subsubsection{Molecular Weight of Extractable $\beta$-Glucan}

Of the three major DF components studied here, $\beta$-glucan was the most sensitive to enzyme-related degradation. $\beta$-Glucan Calcofluor average molecular weight $\left(M_{c f}\right)$ was significantly influenced by rest time $(P<0.001)$, and amount of salt $(P=0.043)$ and flour $(P=0.019)$ in the recipe (Figure 1). For $\beta$-glucan there was a sharp decline in $M_{c f}$ from 0-20 min rest time, followed by a gradual decreasing trend. The average $M_{c f}$ value in porridges made without any rest time was $8.86 \times 10^{5} \mathrm{~g} \mathrm{~mol}^{-1}$ and this decreased to $4.32 \times 10^{5} \mathrm{~g} \mathrm{~mol}^{-1}$ after $60 \mathrm{~min}$ rest time before cooking. The inverse relationship observed here between $M_{c f}$ and extractability shows that extractable $\beta$-glucan is released from the insoluble matrix, while at the same time the molecular weight is decreased. Endogenous $\beta$-glucanases are probably responsible for these effects [22], since heat during cooking of different porridges has been shown not to affect the molecular weight of $\beta$-glucan [14,36]. A small but statistically significant decrease in $M_{c f}$ (from $6.25 \times 10^{5}$ to $5.91 \times 10^{5} \mathrm{~g} \mathrm{~mol}^{-1}$ ) was observed with addition of $1 \mathrm{~g}$ salt (Figure 1). This decrease in $M_{c f}$ might be due to increased activity of endogenous enzymes in the presence of salt. The $M_{c f}$ value also decreased somewhat with increasing flour amount (Figure 1). A possible reason for this decrease might be a change in water content affecting enzyme activity.

The molecular weight distribution profiles of $\beta$-glucan were compared at each time interval at the centre point of flour and salt (Figure 6). The raw flour had the highest proportion of high molecular weight $\beta$-glucan fraction, while in porridges the low molecular weight fraction increased with increasing rest time before cooking. The porridges made without any rest time also showed significant 
degradation compared with flour. This is an indication that endogenous enzymes hydrolyze $\beta$-glucan rapidly and that the majority of this degradation takes place within the first few minutes, as also shown by Andersson et al. [22] in a bread study. Other processing parameters such as dough mixing have been shown to affect $M_{c f}$ significantly too [15]. Processing could therefore influence the structural and molecular properties of $\beta$-glucan. This enzyme-related degradation could be undesirable and may impair the nutritional value of $\beta$-glucan [12].

Figure 6. Molecular weight distribution of $\beta$-glucan in flour and in porridges rested for 0 , 20, 40, $60 \mathrm{~min}$ before cooking ( - flour, _ $0 \mathrm{~min}, \ldots .-20 \mathrm{~min}, \ldots . . .40 \mathrm{~min}$, - - - $60 \mathrm{~min})$.

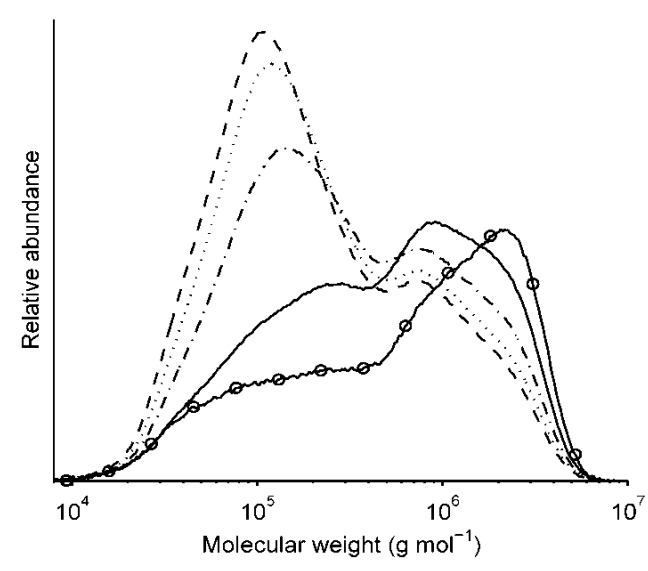

\section{Experimental Section}

\subsection{Materials}

Finely milled whole grain rye flour was purchased from a local supermarket and thoroughly mixed to produce homogeneous fractions. The salt $(\mathrm{NaCl})$ used during porridge making was laboratory grade.

\subsection{Chemicals and Reagents}

Anhydrous sodium acetate was procured from Fluka (Steinheim, Germany). The enzymes used for analysis were obtained from Megazyme (Bray, Ireland). Lactose was obtained from Sigma (Steinheim, Germany).

\subsection{Experiment 1}

\subsubsection{Design of Experiment 1}

A full factorial design was used, with two levels of flour (50 and $35 \mathrm{~g})$ and salt ( 0 and $1 \mathrm{~g})$ and four levels of rest time $(0,20,40,60 \mathrm{~min})$ before cooking (Figure 2). The centre points of salt $(0.5 \mathrm{~g})$ and flour (42.5 g) with all four levels of rest time were carried out in triplicate to account for experimental error. 


\subsubsection{Porridge Making}

Pre-trials were conducted to determine the optimum amounts of flour and water and the optimum heating time to produce good, consistent porridge. The experimental porridges were then prepared according to the design using fixed amount $(180 \mathrm{~mL})$ of water. The water-soaked ingredients were incubated at $20{ }^{\circ} \mathrm{C}$ and stirred for $10 \mathrm{~s}$ every $5 \mathrm{~min}$ to ensure uniform action of the endogenous enzymes. After cooking for $7 \mathrm{~min}$ on a hot plate at intermediate setting, the porridges were transferred to an aluminum container, covered and immediately frozen at $-20{ }^{\circ} \mathrm{C}$. The next day the porridges were freeze-dried for $72 \mathrm{~h}$. Finally, the freeze-dried porridges were milled in a cyclone sample mill (Retsch, Hann, Germany) to pass a $0.5 \mathrm{~mm}$ screen and stored in plastic containers at room temperature for subsequent analysis. This method of porridge making is very similar to that normally used in Scandinavia.

\subsection{Experiment 2}

This experiment was planned to investigate the role of temperature and $\mathrm{pH}$ in $\mathrm{AX}$ degradation. $10 \mathrm{~g}$ finely milled whole grain rye flour (different from the batch used in experiment 1) was weighed and $27 \mathrm{~mL}$ water or $0.5 \mathrm{M}$ sodium acetate buffer was added. The rye flour slurries having pH 6.2 (prepared with water) and 4.5 (prepared with buffer) were incubated for $1 \mathrm{~h}$ at variable temperatures $\left(20,35,45\right.$ and $\left.55^{\circ} \mathrm{C}\right)$ in an oven. The slurries were stirred for 10 s every 5 min to ensure uniform action of the endogenous enzymes. Subsequently the slurries were freeze dried and milled in a cyclone sample mill (Retsch, Hann, Germany) to pass a $0.5 \mathrm{~mm}$ screen.

\subsection{Analytical Methods}

All analytical results are reported on a dry matter basis. Analyses were replicated at least twice on each sample (raw flour and porridges) and the deviation between replicates was generally less than $5 \%$. Dry matter was determined by drying the samples at $105^{\circ} \mathrm{C}$ for $16 \mathrm{~h}$. AX was extracted during enzymatic degradation of starch at $100{ }^{\circ} \mathrm{C}$ and $60{ }^{\circ} \mathrm{C}$ followed by purification of the extract with lichenase and pancreatin before precipitation of $\mathrm{AX}$ with ethanol [2]. AX weight-average molecular weight and number-average molecular weight were determined by high performance size exclusion chromatography coupled with multiple angle laser light scattering and refractive index detectors (Wyatt Technology, Santa Barbara, USA). Molecules with a molecular weight of less than $1.5 \times 10^{5} \mathrm{~g} \mathrm{~mol}^{-1}$ were not included in the calculations, as they lack precision in this analysis. Fructan molecular weight distribution was investigated using high performance anion exchange chromatography with pulsed amperometric detection [28]. In brief, the samples were extracted with $80 \%$ ethanol in a boiling water bath for $1 \mathrm{~h}$. The ethanol was evaporated and the residue was treated with amyloglucosidase (soluble starch $326 \mathrm{U} \mathrm{mL}^{-1}$, E-AMGDF, Megazyme, Bray, Ireland). The amyloglucosidase-treated solution was divided into two aliquots and one was treated with fructanase mixture, E-FRMXLQ (exo-inulinase $2000 \mathrm{U} \mathrm{mL}^{-1}$ and endo-inulinase $200 \mathrm{U} \mathrm{mL}^{-1}$, Megazyme, Bray, Ireland). Both aliquots were filtered through Titan $2^{\circledR}$ HPLC syringe filters $(17 \mathrm{~mm}, 0.45 \mu \mathrm{m}$, Sun Sri, Wilmington, N.C, USA) before chromatography. The distribution was computed based on difference in peak area between non-fructanase and fructanase treated extracts since no reference compounds were available. Calcofluor average molecular weight of $\beta$-glucan was determined using size exclusion chromatography with Calcofluor 
detection according to the method described by Rimsten et al. [37], with a Calcofluor concentration of $0.0025 \%$. With this detection technique, molecules smaller than $10^{4} \mathrm{~g} \mathrm{~mol}^{-1}$ are excluded from the analysis, as these shorter fragments cannot be quantified with precision.

Rye flour and selected porridges (with $42.5 \mathrm{~g}$ flour, $0.5 \mathrm{~g}$ salt and rested for 0 or $60 \mathrm{~min}$ ) were analyzed for major DF components according to the Uppsala method [38], subsequently modified by Andersson et al. [39] for separate analysis of extractable and unextractable DF components. AX values were calculated from the arabinose, xylose, and galactose values, assuming an arabinose/galactose ratio of 0.69 in extractable arabinogalactan [40]. Fructan content was analyzed according to McCleary et al. [41] by a spectrophotometric method using the enzymatic assay kit K-FRUC (Megazyme, Bray, Ireland). The samples were treated with $\alpha$-galactosidase from Aspergillus niger E-AGLAN (Megazyme, Bray, Ireland) before degradation of starch, maltosaccharides, and sucrose to avoid interference by raffinose series oligosaccharides. Total $\beta$-glucan was quantified by an enzymatic method [42], while extractable $\beta$-glucan was calculated by taking into account the area under the curve during molecular weight analysis, as described by Rimsten et al. [37].

\subsection{Statistical Analyses}

The responses from the designed experiment were analysed with regression (GLM procedure in Minitab 15 statistical software, Minitab Inc., State Collage, PA, USA) with factors defined as covariates. The contents of DF components were analysed by one-way ANOVA with the factor resting time. The effect of temperature on the molecular weight of arabinoxylan was evaluated by the GLM procedure with $\mathrm{pH}$ and temperature as factors with temperature defined as covariate.

\section{Conclusions}

This study showed that whole grain rye porridge is an excellent source of both extractable and unextractable DF. During porridge making, notable amounts of resistant starch (in the range of 3\%) were formed, which increased the DF content to more than $23 \%$ of dry matter. The content of other major DF components such as AX, $\beta$-glucan, and fructan did not change significantly. However, the extractability of AX and especially $\beta$-glucan increased significantly when the flour slurry was allowed to rest before cooking. Molecular weight distribution profiles of extractable AX and fructan were remarkably stable in porridges prepared under different conditions, but the molecular weight of extractable $\beta$-glucan greatly decreased during a rest time before cooking. These results clearly show that porridge making is a useful way to prepare whole grain rye for human consumption, especially if prepared without rest-time before cooking, when the intention is to produce a meal with a high content of total DF and extractable DF with retained molecular weight.

\section{Acknowledgements}

The author is grateful to the Higher Education Commission, Pakistan, for a scholarship grant. The Barley Fun Food project is also thanked for supporting the research work. Gunnel Fransson is appreciated for help in analytical work. 


\section{References}

1. Åman, P.; Andersson, A.A.M.; Rakha, A.; Andersson, R. Rye, a healthy cereal full of dietary fiber. Cereal Foods World 2010, 55, 231-234.

2. Andersson, R.; Fransson, G.; Tietjen, M.; Åman, P. Content and molecular-weight distribution of dietary fiber components in whole-grain rye flour and bread. J. Agric. Food Chem. 2009, 57, 2004-2008.

3. Hansen, H.B.; Rasmussen, C.V.; Knudsen, K.E.B.; Hansen, Å. Effects of genotype and harvest year on content and composition of dietary fibre in rye (Secale cereale L.) grain. J. Sci. Food Agric. 2003, 83, 76-85.

4. Vinkx, C.J.A.; Delcour, J.A. Rye (Secale cereale L.) arabinoxylans: A critical review. J. Cereal Sci. 1996, 24, 1-14.

5. Wood, P.J.; Weisz, J.; Blackwell, B.A. Structural studies of $(1 \rightarrow 3),(1 \rightarrow 4)-\beta$-D-glucans by ${ }^{13} \mathrm{C}$-nuclear magnetic resonance spectroscopy and by rapid analysis of cellulose-like regions using high-performance anion-exchange chromatography of oligosaccharides released by lichenase. Cereal Chem. 1994, 71, 301-307.

6. Roberfroid, M.B. Introducing inulin-type fructans. Br. J. Nutr. 2005, 93, S13-S25.

7. Bornet, F.R.J. Fructo-oligosaccharides and other fructans: Chemistry, structure and nutritional effects. In Advanced Dietary Fibre Technology; McCleary, B.V., Prosky, L., Eds.; Wiley-Blackwell: Chichester, UK, 2008; pp. 480-493.

8. EFSA (European Food Safety Authority) Panel on Dietetic Products, Nutrition, and Allergies (NDA). Scientific Opinion on Dietary Reference Values for Carbohydrates and Dietary Fibre. EFSA J. 2010, 8, DOI: 10.2903/j.efsa.2010.1462.

9. National Nutrient Database for Standard Reference, SR 23. Available online: http://www.nal.usda.gov/fnic/foodcomp/search/ (accessed on 15 December 2010).

10. Buttriss, J.L.; Stokes, C.S. Dietary fibre and health: An overview. Nutr. Bull. 2008, 33, 186-200.

11. Kendall, C.W.C.; Esfahani, A.; Jenkins, D.J.A. The link between dietary fibre and human health. Food Hydrocoll. 2010, 24, 42-48.

12. Brennan, C.S.; Cleary, L.J. The potential use of cereal $(1 \rightarrow 3,1 \rightarrow 4)-\beta$-D-glucans as functional food ingredients. J. Cereal Sci. 2005, 42, 1-13.

13. Regand, A.; Tosh, S.M.; Wolever, T.M.S.; Wood, P.J. Physicochemical properties of beta-glucan in differently processed oat foods influence glycemic response. J. Agric. Food Chem. 2009, 57, 8831-8838.

14. Åman, P.; Rimsten, L.; Andersson, R. Molecular weight distribution of beta-glucan in oat-based foods. Cereal Chem. 2004, 81, 356-360.

15. Andersson, A.A.M.; Armö, E.; Grangeon, E.; Fredriksson, H.; Andersson, R.; Åman, P. Molecular weight and structure units of $(1 \rightarrow 3,1 \rightarrow 4)$ - $\beta$-glucans in dough and bread made from hull-less barley milling fractions. J. Cereal Sci. 2004, 40, 195-204. 
16. EFSA (European Food Safety Authority) Panel on Dietetic Products, Nutrition and Allergies (NDA). Scientific Opinion on the Substantiation of Health Claims Related to Beta-Glucans and Maintenance of Normal Blood Cholesterol Concentrations (ID 754,755,757,801,1465,2934) and Maintenance or Achievement of a Normal Body Weight (ID 820,823) Pursuant to Article 13(1) of Regulation (EC) No 1924/2006 on Request from the European Commission. EFSA J. 2009, 7, DOI: 10.2903/j.efsa.2009.1254.

17. Dornez, E.; Cuyvers, S.; Gebruers, K.; Delcour, J.A.; Courtin, C.M. Contribution of wheat endogenous and wheat kernel associated microbial endoxylanases to changes in the arabinoxylan population during breadmaking. J. Agric. Food Chem. 2008, 56, 2246-2253.

18. Rasmussen, C.V.; Hansen, H.B.; Hansen, Å.; Larsen, L.M. pH-, temperature- and time-dependent activities of endogenous endo-[beta]-D-xylanase, [beta]-D-xylosidase and [alpha]-L-arabinofuranosidase in extracts from ungerminated rye (Secale cereale L.) grain. J. Cereal Sci. 2001, 34, 49-60.

19. Poutanen, K. Enzymes: An important tool in the improvement of the quality of cereal foods. Trends Food Sci. Technol. 1997, 8, 300-306.

20. Salmenkallio-Marttila, M.; Hovinen, S. Enzyme activities, dietary fibre components and rheological properties of wholemeal flours from rye cultivars grown in Finland. J. Sci. Food Agric. 2005, 85, 1350-1356.

21. Englyst, H.N.; Macfarlane, G.T. Breakdown of resistant and readily digestible starch by human gut bacteria. J. Sci. Food Agric. 1986, 37, 699-706.

22. Andersson, A.A.M.; Rüegg, N.; Åman, P. Molecular weight distribution and content of water-extractable beta-glucan in rye crisp bread. J. Cereal Sci. 2008, 47, 399-406.

23. Laurikainen, T.; Härkönen, H.; Autio, K.; Poutanen, K. Effects of enzymes in fibre-enriched baking. J. Sci. Food Agric. 1998, 76, 239-249.

24. Kawakami, A.; Yoshida, M.; van den Ende, W. Molecular cloning and functional analysis of a novel 6 \& 1-FEH from wheat (Triticum aestivum L.) preferentially degrading small graminans like bifurcose. Gene 2005, 358, 93-101.

25. Chalmers, J.; Lidgett, A.; Cummings, N.; Cao, Y.; Forster, J.; Spangenberg, G. Molecular genetics of fructan metabolism in perennial ryegrass. Plant Biotechnol. J. 2005, 3, 459-474.

26. van den Ende, W.; Clerens, S.; Vergauwen, R.; van Riet, L.; van Laere, A.; Yoshida, M.; Kawakami, A. Fructan 1-exohydrolases: $\beta$-(2,1)-trimmers during graminan biosynthesis in stems of wheat Purification, characterization, mass mapping, and cloning of two fructan 1-exohydrolase isoforms. Plant Physiol. 2003, 131, 621-631.

27. Marx, S.P.; Nösberger, J.; Frehner, M. Seasonal variation of fructan- $\beta$-fructosidase (FEH) activity and characterization of a $\beta$-(2-1)-linkage specific FEH from tubers of Jerusalem artichoke (Helianthus tuberosus). New Phytol. 1997, 135, 267-277.

28. Rakha, A.; Åman, P.; Andersson, R. Characterisation of dietary fibre components in rye products. Food Chem. 2010, 119, 859-867.

29. Cauvain, S.P. Breadmaking: An overview. In Bread Making: Improving Quality; CRC Press: Boca Raton, FL, USA, 2003; pp. 8-28.

30. Hui, Y.H., Meunier-Goddik, L., Hansen, Å.S., Josephsen, J., Nip, W.-K., Stanfield, P.S., Toldra, F., Eds.; Handbook of Food and Beverage Fermentation Technology; CRC Press, Taylor \& Francis Group: London, UK, 2004; pp. 840-871. 
31. Cleemput, G.; Hessing, M.; van Oort, M.; Deconynck, M.; Delcour, J.A. Purification and characterization of a [beta]-D-xylosidase and an endo-xylanase from wheat flour. Plant Physiol. 1997, 113, 377-386.

32. Meyer, A.S.; Rosgaard, L.; Sørensen, H.R. The minimal enzyme cocktail concept for biomass processing. J. Cereal Sci. 2009, 50, 337-344.

33. Katina, K.; Liukkonen, K.H.; Kaukovirta-Norja, A.; Adlercreutz, H.; Heinonen, S.M.; Lampi, A.M.; Pihlava, J.M.; Poutanen, K. Fermentation-induced changes in the nutritional value of native or germinated rye. J. Cereal Sci. 2007, 46, 348-355.

34. Debyser, W.; Peumans, W.J.; Van Damme, E.J.M.; Delcour, J.A. Triticum aestivum xylanase inhibitor (TAXI), a new class of enzyme inhibitor affecting breadmaking performance. J. Cereal Sci. 1999, 30, 39-43.

35. Goesaert, H.; Elliott, G.; Kroon, P.A.; Gebruers, K.; Courtin, C.M.; Robben, J.; Delcour, J.A.; Juge, N. Occurrence of proteinaceous endoxylanase inhibitors in cereals. Biochim. Biophys. Acta Proteins Proteomics 2004, 1696, 193-202.

36. Beer, M.U.; Wood, P.J.; Weisz, J.; Fillion, N. Effect of cooking and storage on the amount and molecular weight of $(1 \rightarrow 3)(1 \rightarrow 4)-\beta$-D-glucan extracted from oat products by an in vitro digestion system. Cereal Chem. 1997, 74 , 705-709.

37. Rimsten, L.; Stenberg, T.; Andersson, R.; Andersson, A.; Åman, P. Determination of beta-glucan molecular weight using SEC with Calcofluor detection in cereal extracts. Cereal Chem. 2003, $80,485-490$.

38. Theander, O.; Åman, P.; Westerlund, E.; Andersson, R.; Pettersson, D. Total dietary fiber determined as neutral sugar residues, uronic acid residues, and Klason lignin (the Uppsala method): Collaborative study. J. AOAC Int. 1995, 78, 1030-1044.

39. Andersson, A.A.M.; Merker, A.; Nilsson, P.; Sørensen, H.; Åman, P. Chemical composition of the potential new oilseed crops Barbarea vulgaris, Barbarea verna and Lepidium campestre. J. Sci. Food Agric. 1999, 79, 179-186.

40. Loosveld, A.M.A.; Grobet, P.J.; Delcour, J.A. Contents and structural features of water-extractable arabinogalactan in wheat flour fractions. J. Agric. Food Chem. 1997, 45, 1998-2002.

41. McCleary, B.V.; Murphy, A.; Mugford, D.C. Determination of oligofructans and fructan polysaccharides in foodstuffs by an enzymatic/spectrophotometric method: Collaborative study. J. AOAC Int. 1997, 83, 356-364.

42. McCleary, B.V.; Codd, R. Measurement of (1-3)(1-4)- $\beta$-D-glucan in barley and oats: A streamlined enzymic procedure. J. Sci. Food Agric. 1991, 55, 303-312.

(C) 2011 by the authors; licensee MDPI, Basel, Switzerland. This article is an open access article distributed under the terms and conditions of the Creative Commons Attribution license (http://creativecommons.org/licenses/by/3.0/). 